\title{
Kajian Geometrik Interchange Waru Ramp Mojokerto-Sidoarjo
}

\author{
Alyssa Dewiputri Herdiana dan Wahju Herijanto
}

Departemen Teknik Sipil, Institut Teknologi Sepuluh Nopember (ITS)

Corresponding Author: wahjoesoeprapto@gmail.com

\section{ARTIKEL INFO}

\section{Informasi Artikel}

Artikel masuk: 1-8-19

Artikel revisi: 26-12-19

Artikel diterima: 26-12-19

\section{Kata Kunci}

Simpangsusun, Jalan Akses, Tol Surabaya-Mojokerto, Tol Surabaya-Porong

\begin{abstract}
ABSTRAK
Mojokerto dan Sidoarjo merupakan dua kabupaten yang tergabung dalam sebuah kawasan metropolitan di Provinsi Jawa Timur, yaitu Gerbangkertosusila (Gresik-Bangkalan-Mojokerto-Surabaya-SidoarjoLamongan) yang bertujuan untuk mewujudkan pemerataan pembangunan antar Daerah. Untuk mewujudkan tujuan tersebut diperlukan jalan tol yang dilengkapi akses keluar-masuk yang memadai dan tidak menyulitkan para pengendara. Dalam tugas akhir ini penulis mencoba merencanakan ulang interchange yang menghubungkan Mojokerto dan Sidoarjo di kawasan Waru yang sebelumnya pada akhir interchange dinilai berpotensi menyebabkan konflik lalu lintas atau weaving conflict karena pendeknya jarak dari ramp satu ke ramp yang lainnya. Perencanaan ulang ini meliputi desain geometri interchange dan ramp yang baru sehingga diharapkan akan mengurangi weaving conflict dan mengurangi potensi kemacetan yang mungkin terjadi. Dalam prosesnya, metodologi yang digunakan adalah dengan menganalisis pemilihan alternatif ramp dengan menggunakan metode Analytic Hierarchy Process kemudian merencanakan desain geometrik interchange dan ramp menggunakan Peraturan Bina Marga No.007/BM/2009. Perencanaan marka dan rambu lalu lintas berdasarkan Peraturan Menteri No. 13 tahun 2014 dan No. 34 tahun 2014. Dari hasil perencanaan geometrik yang dilakukan, dihasilkan 5 tikungan, yaitu 4 tikungan tipe S-C-S dan satu tikungan tipe S-S dengan jari-jari sebesar $200 \mathrm{~m}$ dan panjang lengkung peralihan sebesar 25,397 m. Sedangkan untuk perencanaan ramp dihasilkan ramp on dengan jari-jari sebesar $400 \mathrm{~m}$ tipe taper dan ramp off dengan jari-jari sebesar $250 \mathrm{~m}$ tipe parallel. Rambu lalu lintas direncanakan terdapat 15 buah dan 3 macam marka.
\end{abstract}

\section{PENDAHULUAN}

Mojokerto dan Sidoarjo merupakan dua kabupaten yang berada di sekitar Kota Surabaya yang telah memberikan kontribusi besar terhadap pertumbuhan dan pergerakan industri di Jawa Timur juga mendukung fungsi Kota Surabaya sebagai hub bagi aktivitas ekonomi dan sosial wilayah Indonesia bagian timur. Mojokerto dan Sidoarjo juga tergabung dalam sebuah kawasan metropolitan di Provinsi Jawa Timur, yaitu Gerbangkertosusila (GresikBangkalan-Mojokerto-Surabaya-Sidoarjo-Lamongan) yang menurut Perda Provinsi Jawa Timur No. 4/1996 tentang RTRW Provinsi Jawa Timur dan Peraturan Pemerintah No. 47/1996 tentang RTRW Nasional, yang bertujuan untuk mewujudkan pemerataan pembangunan antar Daerah.

Pembangunan jalan tol merupakan salah satu bentuk infrastruktur yang dibangun oleh pemerintah dalam rangka pemerataan pembangunan dengan memudahkan masyarakat untuk melakukan mobilitas barang dan jasa dengan baik dan cepat. Jalan tol juga disebut-sebut merupakan mega proyek pemerintah untuk mengurai kemacetan dan dapat menjadi salah satu sumber pemasukan kas negara. Pembangunan jalan tol harus direncanakan se-efektif mungkin sehingga tidak melupakan tujuan awalnya yaitu memperlancar lalu lintas tanpa adanya kemacetan. Pada salah satu jalan interchange di wilayah Waru pada Jalan Tol SurabayaMojokerto yang menghubungkan Kabupaten Mojokerto dan Kabupaten Sidoarjo ditemukan titik pintu masuk (ramp on) dan pintu keluar (ramp off) yang terlalu dekat sehingga dapat menyebabkan konflik lalu lintas (weaving conflict). Oleh karena itu, dalam tugas akhir ini akan direncanakan ulang geometrik interchange yang menghubungkan Kabupaten Mojokerto dan Kabupaten Sidoarjo.

\section{A. Rumusan Masalah}

Dari latar belakang diatas, penulis ingin meninjau segi teknis yaitu

1. Bagaimana menentukan jenis akses yang tepat dan sesuai dengan metode Analytic Hierarchy Process?

2. Bagaimana bentuk geometrik alinemen horizontal yang menjamin keselamatan dan sesuai dengan 


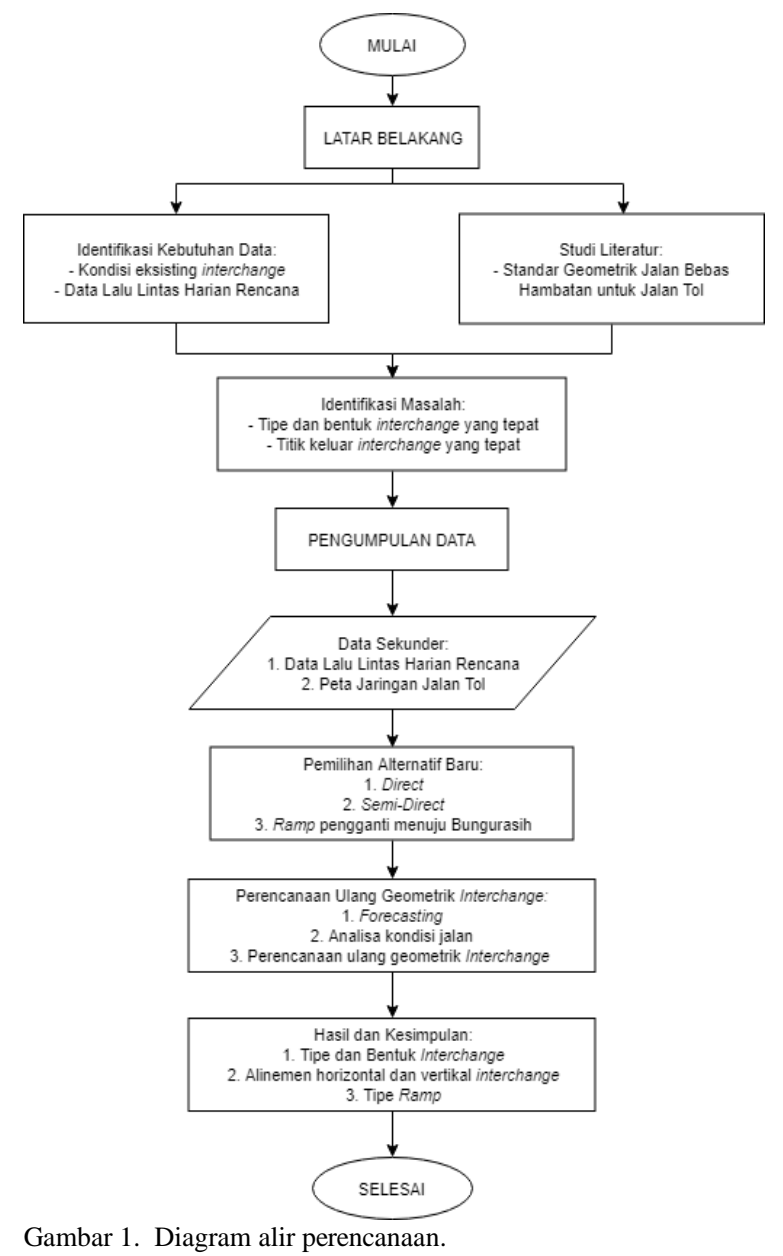

aturan yang berlaku di Indonesia?

3. Bagaimana bentuk geometrik alinemen vertikal yang menjamin keselamatan dan sesuai dengan aturan yang berlaku di Indonesia?

4. Fasilitas apa saja yang diperlukan pada interchange Waru ramp Mojokerto-Sidoarjo?

\section{B. Tujuan Perencanaan}

Tujuan dari Perencanaan adalah:

1. Dapat menentukan jenis akses yang tepat dan sesuai dengan aturan yang berlaku di Indonesia.

2. Dapat merencanakan bentuk geometrik alinemen horizontal yang menjamin keselamatan dan sesuai dengan aturan yang berlaku di Indonesia.

3. Dapat merencanakan bentuk geometrik alinemen vertikal yang menjamin keselamatan dan sesuai dengan aturan yag berlaku di Indonesia.

4. Dapat merencanakan fasilitas yang ada pada interchange Waru ramp Mojokerto-Sidoarjo.

\section{Tinjauan Pustaka}

Pustaka dari perencanaan ini adalah:

1. Analytic Hierarchy Process adalah teori pengukuran melalui perbandingan berpasangan dan bergantung pada penilaian para ahli untuk mendapatkan skala prioritas [1][2].

2. Alinemen horizontal adalah proyeksi garis sumbu jalan pada bidang horizontal. Alinemen horizontal terdiri dari atas bagian lurus dan bagian lengkung (tikungan).

3. Alinemen vertikal adalah proyeksi garis sumbu jalan pada bidang vertikal yang melalui sumbu jalan terdiri dari bagian lurus dan bagian lengkung [3].

4. Fasilitas perlengkapan jalan terdiri dari marka jalan dan rambu lalu lintas [4][5].

\section{METODOLOGI}

Metodologi dalam studi ini dapat dilihat Gambar 1.

\section{DATA DAN ANALISIS DATA}

\section{A. Data Lalu Lintas Harian}

Data lalu lintas harian (LHR) diperoleh dari PT. Jasamarga Surabaya Mojokerto (JSM). Data LHR yang digunakan dalam tugas akhir ini adalah data LHR yang melewati gerbang tol Waru 5 dan menuju arah Mojokerto. Dari data yang didapat, volume LHR pada titik tersebut adalah sebesar 2377 smp/hari.

Analisis volume lalu lintas eksisting adalah hasil perhitungan forecasting volume lalu lintas setiap tahunnya pada eksisting selama 10 tahun dimana volume kendaraan ini akan memengaruhi lebar jalan interchange Waru ramp Mojokerto-Sidoarjo. Volume lalu lintas didapatkan dari volume lalu lintas tahunan dikalikan dengan presentase pertumbuhan kendaraan seperti persamaan berikut:

Volume Kendaraan Tahun ke-n $=$ Volume kendaraan tahun ke $(\mathrm{n}-1)+($ Volume kendaraan tahun ke $(\mathrm{n}-1)$ * Presentase peningkatan kendaraan)

Volume Kendaraan Tahun ke-2019 $=2377+(2377 *$ $4,62 \%)=2487 \mathrm{smp} / \mathrm{hari}$

Rekapitulasi perhitungan volume kendaraan sampai tahun ke-10 dapat dilihat pada Tabel 1.

Tabel 1. Volume Lalu Lintas selama 10 tahun

\begin{tabular}{cc}
\hline \hline Tahun & Q (smp/tahun $)$ \\
\hline 2018 & 2377 \\
2019 & 2487 \\
2020 & 2602 \\
2021 & 2723 \\
2022 & 2849 \\
2023 & 2981 \\
2024 & 3119 \\
2025 & 3264 \\
2026 & 3415 \\
2027 & 3573 \\
2028 & 3739 \\
\hline \hline
\end{tabular}

Garis vertikal boleh ditambahakan. Pernyataan yang menjelaskan seluruh bagian tabel diletakkan pada judul tabel, tidak pada catatan kaki di sini.

${ }^{\mathrm{a}} \mathrm{CR}$ - Constant ratio.

Untuk mendapatkan data lebar jalur, dibutuhkan data volume lalu lintas harian rata-rata [6] pada proyeksi tahun ke-10. Maka data VLHR pada tahun ke-10 sebesar 3739 smp/hari. Lebar jalur yang dapat digunakan berdasarkan peraturan Bina Marga adalah sebesar $7 \mathrm{~m}$.

\section{ALTERNATIF DAN PEMILIHAN TRASE}

\section{A. Alternatif Trase}

Terdapat 3 pilihan alternatif trase yang memungkinkan untuk menjadi pengganti dari trase eksisting, yaitu tipe direct, tipe semi-direct, dan pengganti ramp waru 6.

Kriteria yang dijadikan sebagai bahan pertimbangan adalah sebagai berikut:

1. Panjang jalan trase rencana

2. Elevasi interchange

3. Kemungkinan integrasi jalan tol antarkota 


\section{B. Pemilihan Trase}

Dalam tahap pemilihan trase berdasarkan metode AHP, terdapat beberapa tahapan yang harus dilakukan, yaitu:

1. Pembobotan Kriteria

Pembobotan ditentukan berdasarkan peringkat diberikan dengan rentang nilai 1 s.d. 9 dengan kriteria yang diutamakan diberi nilai lebih tinggi dan diurutkan ke nilai paling rendah. Peringkat akan dipaparkan dalam bentuk matriks di Tabel 2.

\begin{tabular}{cccc}
\multicolumn{4}{c}{ Tabel 2. Pembobotan Kriteria } \\
\hline \hline $\begin{array}{c}\text { Kriteria } \\
\text { Pemilihan }\end{array}$ & Panjang Trase & $\begin{array}{c}\text { Elevasi } \\
\text { Interchange }\end{array}$ & $\begin{array}{c}\text { Intgrasi Tol } \\
\text { Antarkota }\end{array}$ \\
\hline $\begin{array}{c}\text { Panjang Trase } \\
\text { Elevasi }\end{array}$ & 1 & $1 / 3$ & $1 / 5$ \\
$\begin{array}{c}\text { interchange } \\
\text { Integrasi Tol } \\
\text { Antarkota }\end{array}$ & 3 & 1 & $1 / 3$ \\
\hline \hline
\end{tabular}

Masing-masing angka diberi bobot dengan membagi masing-masing angka tersebut dengan jumlah setiap baris. Perhitungan peringkat prioritas disajikan dalam matriks pada Tabel 3.

Tabel 3. Peringkat Prioritas

\begin{tabular}{cccc}
\hline \hline $\begin{array}{c}\text { Kriteria } \\
\text { Pemilihan }\end{array}$ & Panjang Trase & $\begin{array}{c}\text { Elevasi } \\
\text { Interchange }\end{array}$ & $\begin{array}{c}\text { Intgrasi Tol } \\
\text { Antarkota }\end{array}$ \\
\hline $\begin{array}{c}\text { Panjang Trase } \\
\text { Elevasi } \\
\begin{array}{c}\text { interchange } \\
\text { Integrasi Tol } \\
\text { Antarkota }\end{array}\end{array}$ & 0.11 & 0,08 & 0,13 \\
\hline \hline
\end{tabular}

Jumlah angka perkolom adalah peringkat prioritas dari setiap kriteria. Pembobotan prioritas dari setiap kriteria dapat dilihat pada Tabel 4.

\begin{tabular}{cc} 
Tabel 4. Pembobotan Prioritas \\
\hline \hline Panjang Trase & 0,11 \\
\hline Elevasi interchange & 0,26 \\
Integrasi Tol Antarkota & 0,63 \\
\hline \hline
\end{tabular}

2. Menentukan Konsistensi Rasio

Menentukan nilai $\lambda_{\max }$ :

A $x=A x=\lambda_{\max } x$

$\left(\begin{array}{ccc}1 & 1 / 3 & 1 / 5 \\ 3 & 1 & 1 / 3 \\ 5 & 3 & 1\end{array}\right) \cdot\left(\begin{array}{l}0.11 \\ 0.26 \\ 0.63\end{array}\right)=\left(\begin{array}{l}0.320 \\ 0.790 \\ 1.946\end{array}\right)=\lambda_{\max }\left(\begin{array}{l}0.11 \\ 0.26 \\ 0.63\end{array}\right)$

$\lambda_{\max }=$ average $(0.32 / 0.11,0.79 / 0.26,1.95 / 0.63)$

$\lambda_{\text {max }}=3.04$

Menentukan nilai konsistensi index (CI):

$\mathrm{n}=3$

$$
\begin{aligned}
& C I=\frac{d_{\max }-n}{\mathrm{~d}-1} \\
& C I=\frac{\mathrm{a} d \mathrm{~d}-\mathrm{a}}{\mathrm{a}-1}=0.019
\end{aligned}
$$

Menentukan Konsistensi Rasio (CR):

$$
\begin{aligned}
& C R=\frac{C I}{R I} \\
& C R=\frac{\text { O.019 }}{3}=0.037
\end{aligned}
$$

Nilai $\mathrm{CR}=0.037 \leq 0.1$, maka OK.

\section{Peringkat Kriteria}

Pembobotan alternatif dilakukan pada masing-masing kriteria dalam Tabel 5.

\section{Peringkat Kriteria}

Alternatif terpilih didapatkan berdasarkan nilai terbesar dari hasil perkalian matriks prioritas dengan pembobotan kriteria.

$\begin{gathered}\text { direct } \\ \text { remi }- \text { direct }\end{gathered}\left(\begin{array}{lll}0.2885 & 0.2728 & 0.400 \\ 0.2480 & 0.1817 & 0.400 \\ 0.4636 & 0.5456 & 0.200\end{array}\right) \cdot\left(\begin{array}{l}0.11 \\ 0.26 \\ 0.63\end{array}\right)=\left(\begin{array}{l}0.3550 \\ 0.3270 \\ 0.3180\end{array}\right)$

Dari perhitungan diatas, maka trase yang dipilih adalah trase tipe direct.

Tabel 5. Pembobotan masing-masing kriteria

\begin{tabular}{cccc}
\hline \hline & Panjang Trase & $\begin{array}{c}\text { Elevasi } \\
\text { Interchange }\end{array}$ & $\begin{array}{c}\text { Intgrasi Tol } \\
\text { Antarkota }\end{array}$ \\
\hline $\begin{array}{c}\text { Direct } \\
\text { Semi-direct } \\
\text { Ramp }\end{array}$ & 0,2885 & 0,2728 & 0,400 \\
pengganti & 0,2480 & 0,1817 & 0,400 \\
\hline \hline
\end{tabular}

\section{PERENCANAAN GEOMETRIK}

\section{A. Perencanaan Interchange}

Perencanaan ramp atau jalur penghubung antara simpangsusun Jalan Tol Surabaya-Mojokerto dan Jalan Tol Surabaya-Porong dalam Tugas Akhir ini direncanakan dengan tipe 2/1UD atau 2 lajur 1 arah tidak terbagi, dengan lebar jalur yang direncanakan 7 meter dengan lebar tiap lajur 3.5 meter dan kecepatan rencana sebesar

\begin{tabular}{|c|c|c|c|}
\hline No. & Parameter & Desain & Satuan \\
\hline 1 & Kecepatan Rencana & 40 & $\mathrm{~km} / \mathrm{jam}$ \\
\hline \multirow[t]{6}{*}{2} & Potongan Melintang & & \\
\hline & Lebar Lajur & 3.5 & $\mathrm{~m}$ \\
\hline & Tipe & 2/1UD & \\
\hline & Kemiringan Melintang Normal & 2 & $\%$ \\
\hline & $\begin{array}{l}\text { Tinggi Ruang Bebas Vertikal } \\
\text { Minimum }\end{array}$ & 5 & $\mathrm{~m}$ \\
\hline & Superelevasi Maksimum & 10 & $\%$ \\
\hline \multirow[t]{2}{*}{3} & Jarak Pandang & & \\
\hline & Jarak Pandang Henti Minimum & 28,92 & $\mathrm{~m}$ \\
\hline \multirow[t]{4}{*}{4} & Parameter Alinemen Horizontal & & \\
\hline & Jari-Jari Tikungan Minimum & 50 & $\mathrm{~m}$ \\
\hline & Jari-Jari Tikungan Pakai & 200 & $\mathrm{~m}$ \\
\hline & $\begin{array}{l}\text { Panjang Lengkung Peralihan } \\
\text { Minimum }\end{array}$ & 25,397 & $\mathrm{~m}$ \\
\hline \multirow[t]{3}{*}{5} & Parameter Alinemen Vertikal & & \\
\hline & Landai Maksimum & 3.04 & $\%$ \\
\hline & Panjang Lengkung Minimum & 24 & $\mathrm{~m}$ \\
\hline
\end{tabular}
$40 \mathrm{~km} / \mathrm{jam}$. Kriteria desain perencanaan dapat dilihat pada Tabel 6.

Tabel 6. Kriteria Desain Perencanaan

Pada alinemen horizontal terdapat Point of Interest (PI) sebanyak 5 buah dengan rincian pada Tabel 7.

\begin{tabular}{cccc}
\multicolumn{4}{c}{ Tabel 7. Alinemen Horizontal } \\
\hline \hline & Tipe & R (m) & Ls (m) \\
\hline PI -1 & S-C-S & 200 & 25,397 \\
PI -2 & S-C-S & 200 & 25,397 \\
PI - 3 & S-C-S & 100 & 25,397 \\
PI -4 & S-S & 100 & 25,397 \\
PI -5 & S-C-S & 100 & 25,397 \\
\hline \hline
\end{tabular}

Alinemen Vertikal direncanakan dengan Point Vertical of Interest sebanyak 3 buah dengan rincian pada Tabel 8 .

Tabel 8. Alinemen Vertikal

\begin{tabular}{cccc}
\hline \hline & Tipe & Ss $(\mathrm{m})$ & Ls $(\mathrm{m})$ \\
\hline PVI -1 & Cembung & 28,92 & 150 \\
PVI -2 & Cekung & 29,66 & 24
\end{tabular}




\begin{tabular}{llll} 
PVI -3 & Cekung & 45,47 & 24 \\
\hline \hline
\end{tabular}

Daerah kebebasan samping dihitung dengan mempertimbangkan jarak pandang henti yang lebih kecil dari panjang lengkung tikungan. Dengan menggunakan dimensi kendaraan terbesar, yaitu truk 5 as [6], rincian perhitungan daerah kebebasan samping dan pelebaran pada tikungan dapat dilihat pada Tabel 9.

Tabel 9. Daerah Kebebasan Samping dan Pelebaran pada Tikungan

\begin{tabular}{ccc}
\hline & $\mathrm{M}(\mathrm{m})$ & $\omega(\mathrm{m})$ \\
\hline PI -1 & 0,527 & 2 \\
PI -2 & 0,554 & 2 \\
PI -3 & 2,618 & 3 \\
PI -4 & 2,618 & 3 \\
PI -5 & 2,618 & 3 \\
\hline \hline
\end{tabular}

B. Perencanaan Ramp

Direncanakan ramp menggunakan 1 radius tikungan dengan rincian pada Tabel 10.

Tabel 10. Daerah Kebebasan Samping dan Pelebaran pada Tikungan

\begin{tabular}{ccccc}
\hline \hline & $\mathrm{R}$ & Tipe & $\begin{array}{c}\text { Lajur } \\
\text { Percepatan/perlambatan }\end{array}$ & Taper \\
\hline $\begin{array}{c}\text { Ramp } \\
\text { On }\end{array}$ & 400 & $\begin{array}{c}\text { Parall } \\
\text { el }\end{array}$ & 145 & 225 \\
$\begin{array}{c}\text { Ramp } \\
\text { Off }\end{array}$ & 250 & $\begin{array}{c}\text { Parall } \\
\text { el }\end{array}$ & 285 & 113 \\
\hline \hline
\end{tabular}

\section{PERENCANAAN FASILITAS JALAN}

\section{A. Perencanaan Rambu Jalan}

Direncanakan rambu lalu lintas pada perencanaan ini terdapat 15 buah rambu yang terdiri dari rambu peringatan, rambu larangan dan rambu petunjuk.

\section{B. Perencanaan Marka Jalan}

Direncanakan marka jalan pada perencanaan ini terdapat 3 macam marka, yaitu marka memanjang garis putusputus, marka memanjang garis menerus, dan marka serong garis utuh dengan chevron.

\section{KESIMPULAN DAN SARAN}

\section{A. Kesimpulan}

Berdasarkan perencanaan yang telah dilakukan pada bab-bab sebelumnya, maka dapat didapatkan kesimpulan sebagai berikut:
1. Pada tahap pemilihan alternatif trase alternatif yang memiliki nilai pembobotan paling tinggi yaitu alternatif direct.

2. Perencanaan alinemen horizontal direncanakan terdapat 5 buah Point of Interest dengan jari-jari 200 meter dan panjang lengkung peralihan 25,397 meter.

3. Perencanaan alinemen vertikal direncanakan memiliki 3 buah Point Vertical of Interest dengan kelandaian maksimum $2,25 \%$ pada tanjakan dan $3,04 \%$ pada turunan serta panjang lengkung minimal sebesar 24 meter.

4. Rambu yang digunakan pada perencanaan ini adalah sebanyak 15 buah dan marka jalan yang digunakan ada 3 macam, yaitu marka memanjang garis putus-putus, marka memanjang garis menerus dan marka serong.

\section{B. Saran}

Berdasarkan analisis selama proses penyusunan perencanaan ini, beberapa saran yang dapat penulis sampaikan adalah:

1. Dalam memilih kriteria untuk pemilihan alternatif, akan lebih memudahkan jika menggunakan data-data kuantitatif.

2. Dalam merencanakan trase dengan ketinggian, perlu diperhatikan elevasi dari jalan eksisting dan tinggi konstruksi rencana.

\section{DAFTAR PUSTAKA}

[1] T. . Saaty, "How to Make a Decision: The Analytic Hierarchy Process," Interfaces (Providence)., vol. 24, no. 6, pp. 19-43, 1994.

[2] T. L. Saaty, "Decision Making with The Analytic Hierarchy Process," 2008.

[3] Departemen Perhubungan, "Standar Geometri Jalan Bebas Hambatan untuk Jalan Tol," Jakarta, 2009.

[4] Republik Indonesia, "Peraturan Menteri Republik Indonesia No. 13 Tahun 2014 tentang Rambu Lalu Lintas," Jakarta, 2014.

[5] Republik Indonesia, "Peraturan Menteri Republik Indonesia No. 34 Tahun 2014 tentang Marka Jalan,” Jakarta, 2014.

[6] Anonymous, "Undang-Undang Republik Indonesia Nomor 38 Tahun 2004 Tentang Jalan,” Jakarta, 2004. 